\title{
Professional branding of a university lecturer
}

\author{
Aleksey Khrulyov ${ }^{1}$, and Alina Khrulyova ${ }^{2 *}$ \\ ${ }^{1}$ V. I. Vernadsky Crimean Federal University, Department of Socio-pedagogical Technologies and \\ Pedagogy of Deviant Behavior, 298600, Simferopol, Russian Federation \\ ${ }^{2}$ V. I. Vernadsky Crimean Federal University, Department of Foreign Philology and Methods of \\ Teaching, 298600, Simferopol, Russian Federation
}

\begin{abstract}
The paper is devoted to the conditions for the status raising of a modern lecturer through professional branding. The article substantiates the importance of the lecturer's brand for his successful professional activity. The author examines new opportunities for a lecturer-scientist, that the creation of his own brand open up. The stages of development of the lecturer's personal brand are determined.
\end{abstract}

\section{Introduction}

In the modern labor market, the role of specialists who are able to generate knowledge, actively and creatively implement it in various fields of activity is increasing. One of the conditions for increasing the status of a modern lecturer of an educational institution of higher education is the creation of a personal brand. The activities of a lecturer include communication with a large audience of students, which implies the formation of their own professional image, the positive reputation formation, and is also a platform for popularizing the profession of "lecturer" and increasing its relevance.

Professional branding is a new step in the professional development of a lecturer, it presupposes a holistic process of forming a lecturer's personal brand, that consists in creating an attractive, socially recognized, recognizable and recognized image of a lecturerscientist's personality in his professional field [1].

A lot of research is devoted to creating a personal brand in the field of business, economics, marketing. The issues of professional personality branding were considered by R. Brown [2], O.M. Gurtovenko [3], M. Hamlin, P. Kotler, I. Rein, M. Stoller [4], A.A. Kiselev, V.D. Suhov [5], G.G. Levkin [6], N.V. Savina [7], T. Waller [8].

The purpose of this paper is to substantiate the importance of developing a lecturer's personal brand for his successful professional activity. Goal setting involves solving the following tasks:

- to consider new opportunities for raising the status of a lecturer-scientist, which opens up the creation of your own brand;

- determine the stages of development of the lecturer's personal brand.

\footnotetext{
* Corresponding author: malinayalta@yandex.ru
} 


\section{Methods}

When writing an article, methods of analysis of scientific literature, periodic articles, and publications on the topic were used.

\section{Results}

Successful academics, experienced educators who are interested in using their name as a brand and marketing tool can benefit from professional branding for:

- open interaction with stakeholders, audiences, expanding the network of professional contacts, including in a remote format [9];

- formation of a lecturer's positive image;

- gaining prestige in scientific circles through participation in symposia, forums, conferences;

- expanding the scope of activity and influence [10];

- development of alternative methods, courses and distance programs;

- conducting your own master classes, trainings, seminars for target audiences;

- promotion (including commercial) of their own products of intellectual activity [11].

The development of a teacher's personality is associated not only with the formation of an individual professional image, but also with a personal brand in a competitive educational environment. To study the level of competitiveness, 41 teachers of the Humanities and Education Science (branch) Academy of V.I. Vernadsky Crimean Federal University in Yalta.

To study the level of competitiveness, the method of V.I. Andreev "Assessment of the person's level of competitiveness"

When answering the test questions, it was necessary to choose one of the answer options that was the most suitable for the respondent.

1. I know what I want to achieve in the next $2-3$ years.

a) Yes, b) rather yes, c) hard to say, d) rather no, e) no.

2. I appreciate professional, practical and adventurous people.

a) Yes, b) rather yes, c) hard to say, d) rather no, e) no.

3. I know in what area I can earn decent money.

a) Yes, b) rather yes, c) hard to say, d) rather no, e) no.

4. I have enough energy to complete the task.

a) Yes, b) rather yes, c) sometimes, d) rather no, e) no.

5. I get tired after work.

a) Yes, b) rather yes, c) sometimes, d) quite often, e) no.

6. My parents and teachers thought I was diligent.

a) Yes, b) often, c) sometimes, d) rather no, e) no.

7. I manage to find an unexpectedly simple and even original solution with an insoluble problem.

a) Yes, b) relatively often, c) sometimes, d) rarely, e) no.

8. I quickly learn new activities.

a) Yes, b) most often, c) when how, d) not always, e) no.

9. I am the initiator of innovations in our team.

a) Yes, b) most often, c) sometimes, d) very rarely, e) no.

10. I am able to take risks, even if the odds of success are very low.

a) Yes, b) rather yes, c) sometimes, d) most likely no, e) no.

11. My friends consider me a determined person.

a) Yes, b) rather yes, c) who how, d) rather no, e) no. 
12. Buying an expensive but necessary thing, I make a decision for myself, relying on my taste.

a) Yes, b) most often yes, c) sometimes, d) often consult, e) consult almost always.

13. I express my opinion, even if someone does not like it.

a) Yes, b) rather yes, c) sometimes, d) most likely no, e) no.

14. In discussions and disputes, I often manage to insist on my own.

a) Yes, b) rather yes, c) sometimes, d) most likely no, e) no.

15. When making a responsible decision, I rely only on myself and do not consult with anyone.

a) Yes, b) most often yes, c) sometimes, d) most often no, e) no.

16. Among friends I am the "soul of the company" and I like it.

a) Yes, b) rather yes, c) sometimes, d) rarely, e) no.

17. I can easily connect with new people.

a) Yes, b) often, c) sometimes, d) rarely, e) no.

18. I prefer to take responsibility in leading people than to obey anyone.

a) Yes, b) rather yes, c) sometimes, d) most likely no, e) no.

19. I am systematically engaged in self-education, self-development of my personal qualities.

a) Yes, b) rather yes, c) sometimes, d) very weakly and rarely, e) no.

20. I keep a diary where I plan my life, analyze my mistakes.

a) Yes, b) often, c) periodically, d) very rarely, e) no.

21. If I have achieved something, it is thanks to self-education and self-development.

a) Yes, b) most likely yes, c) I am at a loss to answer, d) most likely no, e) no.

22. In the evening after a working day, I fall asleep:

a) very quickly, b) relatively quickly, c) it depends, d) sometimes I suffer from insomnia, e) I often suffer from insomnia.

23. If someone is rude to me, then I quickly forget about it.

a) Yes, b) most likely yes, c) it depends, d) most likely no, e) no.

24. I strive and I manage not to involve myself in conflicts.

a) Yes, b) most likely yes, c) ir depends, d) most likely no, e) no.

25. Do your friends, colleagues at work consider you as a person with a "perspective" (in terms of professional growth)?

a) Yes, b) rather yes, c) it depends, d) most likely no, e) no.

26. How often, on your own initiative, do you participate in discussions, seminars, conferences?

a) Often, b) relatively often, c) periodically, d) relatively rarely, e) I do not participate.

27. Professionally (in terms of professional self-determination and professional development) in the last two years I have a promotion.

a) Yes, b) most likely yes, c) hard to say, d) most likely no, e) no.

28. I believe that work should be done carefully and efficiently or not done at all.

a) Yes, b) most often, c) not every job requires the same thoroughness, d) I do not do everything equally well, e) I do everything quickly, but not with a high quality.

29. I can repeatedly redo the same work, make qualitative improvements.

a) Yes, b) most often, c) it depends, d) rather not, e) no.

30. Have you ever had a case when your manager asked you to do the work again?

a) I don't remember something like that, b) very rarely, c) periodically, d) relatively often, e) very often.

Then convert the results of your answers into points: $a=5$ points, $6=4$ points, $b=3$ points, $d=2$ points, $d=1$ point.

If you add up the number of points scored, you will get a number that ranges from 30100 points. 
The correspondence of points to the level is presented in the Table 1.

Table 1. Levels of competitiveness.

\begin{tabular}{|c|l|}
\hline Points & Level of competitiveness \\
\hline $30-42$ & $1-$ very low \\
\hline $43-57$ & 2 - low \\
\hline $58-70$ & 3 - below average \\
\hline $71-83$ & $4-$ slightly below average \\
\hline $84-96$ & 5 - average \\
\hline $97-109$ & 6 - slightly above average \\
\hline $110-122$ & 7 - above average \\
\hline $123-137$ & 8 - high \\
\hline $138-150$ & 9 - very high \\
\hline
\end{tabular}

Conducted on the basis of V.I. Andreev's research showed that the average score in this group of interviewed lecturers' is 110 points. This suggests that the level of competitiveness of person is above average.

Of the possible 150 points, one participant showed the maximum result -140 points, which, according to Andreev's competitiveness scale, corresponds to a very high level of competitiveness and is 3\% of the total indicator.

The levels of the lecturers' competitiveness are presented on the Figure 1.

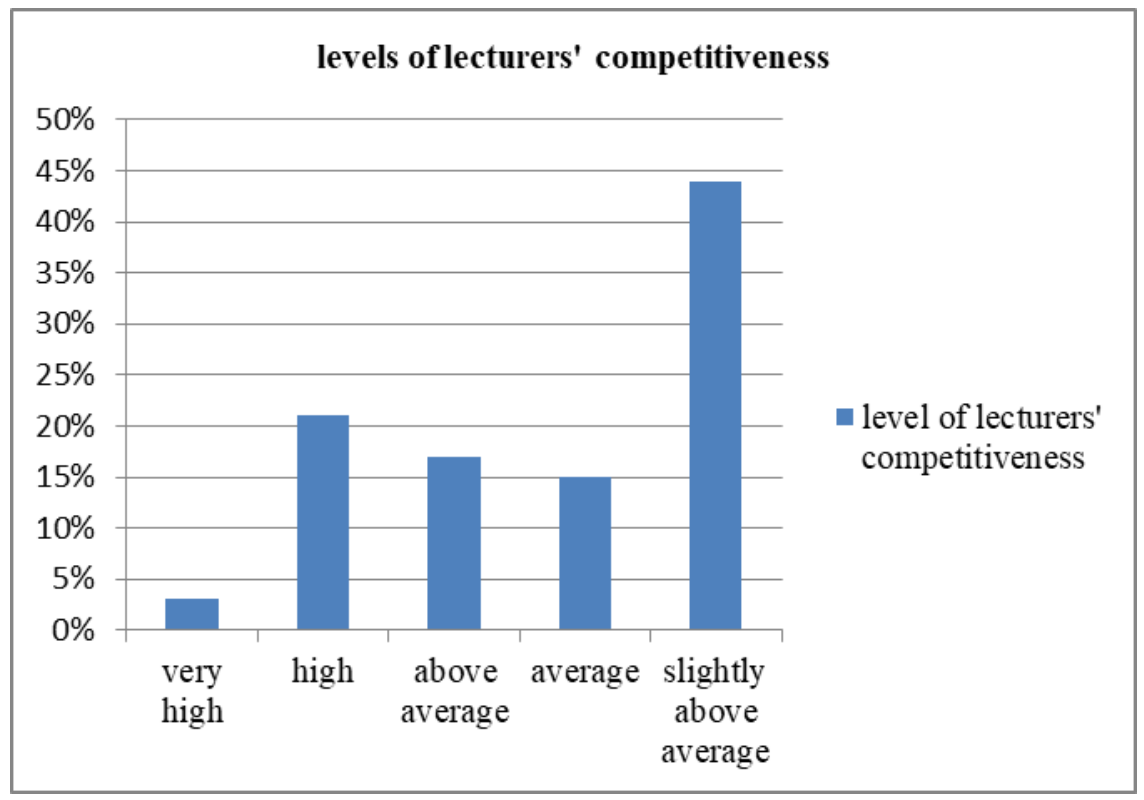

Fig.1. Levels of lecturers' competitiveness.

$21 \%$ of the research participants showed a high level, while the minimum score was 86 , which refers to the average level of competitiveness, as a result of which $15 \%$ of respondents belong.

$17 \%$ of lecturers have a level of competitiveness - above average.

Most lecturers, according to the methodology proposed by slightly below average V.I. Andreev, have a slightly above average level of competitiveness, that is, $44 \%$ (Fig. 1). 
Analysis of the results according to V. I. Andreev's methodology "Assessment of the person's level of competitiveness" shows that the lecturers' level of competitiveness is above average.

Thus, we can conclude that the lecturers who participated in the study have the ability to prove themselves competitive in the labor market.

Forming a lecturer's brand takes a long time, investing significant mental effort, and goes through several stages: from generating an idea to creating a personal brand. As a result, the lecturer gains recognition, a high degree of confidence in the results of his intellectual activity, constantly arouses interest in his professional activity.

In educational institutions of higher education in Russia, attention is focused on the research activities of the teaching staff, in particular on developments and inventions that require concentration of forces and intellectual abilities of first-class specialists, scientists with academic degrees and titles, a positive reputation and status in the science field. [12]. Thus, universities are interested in the availability and involvement of scientists, whose name is a brand. The results of their intellectual work are converted into material for educational pro-grams, used for didactic purposes, thereby becoming the property of not only the author, but also the educational organization in which the lecturer works.

Forming a lecturer brand includes five sequential stages:

1. Positioning of the scientist and his work in the intellectual property market.

2. Development of a lecturer brand strategy.

3. Development of content, brand ideas.

4. Personality analysis and brand name creation.

5. Research and analysis of the attitude of the scientist to the personal brand (brand testing).

The first stage involves the search for your own niche, in which it is most favorable to carry out your own scientific activity. At this stage, the possibilities and potential for the development of the lecturer's scientific activity outside the educational organization of higher education are assessed, the lecturer's personal website is created, registration is carried out on scientific portals and professional communities, the bases of scientific citation on a national and international scale are analyzed [13]. The lecturer answers the following questions:

1. Who is the target audience for the brand?

2. Why is it necessary to form a personal brand, what benefits can the lecturer himself and the target audience receive?

3. What is the purpose of creating your own lecturer brand?

4. Does the presence of a brand allow to protect directly its owner in a competitive environment?

The second step is to develop a lecturer brand strategy. Strategic planning involves the creation of a personal mission, the formation of an idea of the lecturer's activities among the target audience, and the organization of feedback with them.

The third stage is aimed at developing the content, the idea of the lecturer's brand, which is a reflection of the fact that the personality of the scientist deserves to acquire this status and has unique abilities that distinguish it from competitors. The attention of potential consumers can be attracted by the dissemination of information about the conduct of copyright master classes, trainings, scientific games, including in a remote format.

The fourth stage is characterized by the analysis of personal benefits and the creation of the lecturer's brand name.

When positioning the personality of a scientist, the following indicators are important: academic titles and degrees, educational level, professional experience and specialization, personal qualities. The name of the brand is significant, since by the name consumers can 
easily identify the field of activity of a scientist, determine his works and products of intellectual activity [14].

All scientific works of the author can be protected by a special symbol - the "copyright" sign. When the name is recognizable to a wide audience, it can turn into a brand. The symbolic designation of the lecturer's name can act as a means of individualization, be registered and act as a trademark [15].

The fifth stage involves research and analysis of the attitude to the scientist's personal brand. At this stage, the degree of popularization of the scientist's intellectual products is checked by studying sales statistics, opinions about the author and his works are spread, and the effectiveness of the scientist's brand feedback with the target audience is analyzed, the benefits that the end consumer receives from the use of copyright intellectual products are assessed.

Developing a brand in stages allows you to create a large-scale, powerful brand. It is also worth focusing on the fact that the main provisions of the theory of imageology make it possible to more clearly and rationally carry out the development, improvement, modification or correction of the lecturer's personal brand [16].

One of the factors in the formation of a successful lecturer brand is goal-setting. The definition of goals should be guided by their achievement both in the short term (for example, making a presentation at an international conference), and in the long term - for the long term (advanced training, obtaining an academic title, degree) [17].

Lecturers of educational institutions of higher education can promote their own intellectual products in the following way: release electronic versions of their author's educational materials, lectures, including audio and video formats available for download on mobile de-vices, tablets, as a separate application for Android, iOS platforms; to develop an educational site with which you can organize the pedagogical activities of students; post copyright materials on various scientific Internet resources, as well as on social networks for free and paid access.

Regardless of the level occupied by an individual lecturer, scientist, the fundamental goal for each is not only the creation of his own brand, but the subsequent maintenance of the image of a well-recognized personal professional brand.

\section{Conclusion}

Thus, in recent years, the scientific achievements of lecturers-scientists, their contribution to science, have become increasingly important. Of particular relevance is the activity aimed at developing a personal brand of a scientist, which ensures recognition and perception of his personality, as well as the author's product of intellectual activity.

The opportunities that open up for the lecturer, due to the development of a personal brand, are designed to raise the status of a modern lecturer, to strengthen his importance in the scientific community. The proposed stages of the brand formation process contribute to the structuring of professional activities and are a practical tool aimed at the professional growth of a higher school lecturer. A promising area of further work is the study of technologies for the development of a lecturer's personal brand in social networks.

\section{References}

1. T. Waller, An Introduction to Personal Branding, Personal Brand Management, p. 1-16 (2020)

2. R. Brown, Reputation management. Business Information Review. Sage journals, 27(1), 56-64 (2010) 
3. O.M. Gurtovenko, G.G. Levkin, The brand of the teacher of a higher education institution, 6 (18), 55-61 (2014)

4. F. Kotler, I. Rein, M. Hamlin, M. Stoller, Personal branding. Personal popularity technologies (2008)

5. V.D. Suhov, A.A. Kiselev, Development of an algorithm for creating a personal brand of a university teacher, Theoretical economics, 8 (56), 76-86 (2019)

6. G.G. Levkin, O.M. Gurtovenko, The brand of the teacher of a higher educational institution: the basic ways of formation and promotion, Brand-management, 5, 268-280 (2014)

7. N.V. Savina, Branding as a Pedagogical Technology, Pedagogical excellence and pedagogical technology, 2 (8), 69-70 (2016)

8. T. Waller, Personal Brand Reputation Management, Personal Brand Management, pp. 123-139 (2020)

9. L.P. Inozemtseva, The teacher's image as a component of his professional personality, Bulletin of the Chelyabinsk State University. Philology. Art history 24 (57), 231-232 (2011)

10. E.G. Zhuldibin, Technologies for promoting the teacher's personal brand in social networks, Actual problems of aviation and astronautics, p. $771-773$ (2019)

11. T.N. Patrahina, K.S. Vyalkova, The concept of "personal brand", areas of its application: theoretical aspects, Young Researcher, 2, 294-297 (2015)

12. L. Petrov, Brand Called You, http://leonidpetrov.ru/blog/articles?post=brend-imenisebja-sozdanie-i-prodvizhenie-lichnogo-brenda

13. T. Peters, The Brand Called You, http://www.fastcompany.com/28905/brand-called-you

14. A. Noruzi, S. Shahpour, Personal Branding for Authors, Researchers, and Professors, Chapar Publication (2020)

15. J. Cohen, T. Kenny, Personal Branding, Producing New and Digital Media, p. 213-256 (2020)

16. M. Zayats, Was ist Digital Personal Branding?, Digital Personal Branding, p. 11-25 (2020)

17. T. Waller, Marketing Personal Brands, Personal Brand Management, p.69-89 (2020) 